\title{
Thermal Dissociation of Urethanes
}

\author{
Yuhsuke KAWAKAMI,* R. A. N. MURTHY, \\ and Yuya YAMASHITA \\ Department of Synthetic Chemistry, \\ Faculty of Engineering, Nagoya University, \\ Furo-cho, Chikusa-ku, Nagoya 464, Japgn.
}

(Received June 30, 1980)

\begin{abstract}
Model urethanes of phenol and bisphenol were synthesized, and their thermal dissociation was studied. The thermodynamic parameters of dissociation were determined. These studies have been extended to cover two polyurethane polymers in order to determine the number of urethane bonds cut. Some comments are also made on the trapping of liberated isocyanate.

KEY WORDS Polyurethane / Thermal Dissociation / Thermodynamic Parameters / End Capping / Trapping of Isocyanates /
\end{abstract}

Organic compounds having aromatic urethane linkages undergo facile dissociation, ${ }^{1}$ liberating the isocyanate, in protic solvents ${ }^{2-5}$ or mineral oil. ${ }^{6}$ Reversible dissociation has also been observed in aprotic solvents ${ }^{7}$ and the thermodynamic parameters for the equilibrium dissociation of urethanes in an aprotic solvent have also been reported. ${ }^{8}$ It is interesting to note that so far, all such studies have been focussed only on aryl monourethanes and no data pertaining to the higher urethanes is available, except for a patent ${ }^{9}$ on the solution pyrolytic studies of toluene-2,4-diisocyanate bisurethanes. We believe that the dissociation of bis, and higher urethanes will be not only of academic interest but also important in understanding the polymer dissociation characteristics as well as in designing the recyclable elastomer.

In the present work, therefore, a study is made of the equilibrium thermal dissociation of simple aryl bisurethanes in diglyme (diethylene glycol dimethyl ether) at different temperatures. The dissociation was found to be rapid and reversible, reaching a equilibrium quickly (in approximately $7-20 \mathrm{~min}$ utes depending on the temperature employed). This study has been extended to cover two polyurethane polymers.

* To whom correspondence to be given.

\section{EXPERIMENTAL}

\section{General Remarks}

Infrared (IR) measurements were made with a JASCO IRA-1 grating spectrophotometer using $0.1 \mathrm{~mm} \mathrm{NaCl}$ cells. The molecular weights of the polymers were determined by GPC (TOYO SODA HLC 802 UR) using polystyrene gel columns, viz., polystyro G2000 H8 (exclusion limit $2.5 \times 10^{2} \AA$ ) and $\mathrm{G} 3000 \mathrm{H} 8$ (exclusion limit $1.5 \times 10^{3} \AA$ ) grade (TP/F 8000 ) columns of length $610 \mathrm{~mm}$ each, and tetrahydrofuran (THF) solvent. The molecular weights were calibrated with reference to polystyrene standards. For determining the molecular weight of the dissociated polymers, the dissociated polymer-diglyme solution, after cooling in dry ice-acetone bath and subsequent warming to room temperature, was divided into two parts; one part was suitably diluted with THF for gel-permeation chromatography (GPC) measurement (see DISCUSSION part) while the other part was used for the IR measurement.

\section{Materials}

Diphenylmethane-4,4'-diisocyanate (MDI) and phenyl isocyanate were purified by vacuum distillation. Bisphenol-A was recrystallized from boiling toluene. Poly(oxy-1,4-butanediyl)- $\alpha$-hydro- $\omega$ hydroxy [Poly(oxytetramethylene)] of molecular 
weights 856 (PTMG-856) and 2000 (PTMG-2000) were dried under vacuum at $100^{\circ} \mathrm{C}$ for two hours prior to use. Diglyme was distilled over $\mathrm{LiAlH}_{4}$ under reduced pressure and stored under nitrogen. All other solvents were purified by known methods.

\section{Synthesis of Urethane Model Compounds}

The model compounds used in this study, and synthesized according to Hegarty and Frost, ${ }^{11}$ are shown below.

Structures and melting points of urethane model compounds

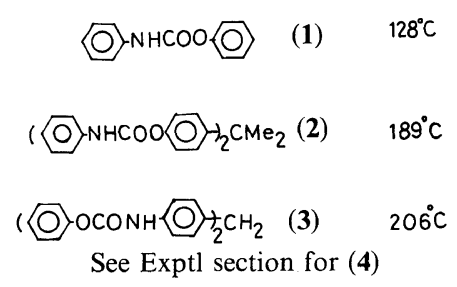

All these compounds showed satisfactory analyses for the elements analyzed.

\section{Synthesis of Polyurethane Polymers}

The polyurethane polymers were synthesized in two stages: the prepolymer synthesis and the chain extension with bisphenol-A. The prepolymers were prepared by heating 2 moles of MDI and 1 mole of poly(oxytetramethylene) in bulk under $\mathrm{N}_{2}$ at $100^{\circ} \mathrm{C}$ for $3 \mathrm{~h}$.

$$
2 \mathrm{MDI}+\mathrm{HO}-\mathrm{R}-\mathrm{OH} \longrightarrow \underset{\text { Prepolymer }}{\mathrm{OCN}-\mathrm{R}^{\prime}-\mathrm{NCO}}
$$

The prepolymer was identified by IR (-NCO group strongly absorbs at $\left.2260-2280 \mathrm{~cm}^{-1}\right)$ and by titration of the unreated -NCO groups by the amine equivalent method. The results of the titration are as follows.

From PTMG-856: \%-NCO, found 6.31, 6.27 (calcd 6.20)

From PTMG-200: \%-NCO, found 3.41, 3.50 (calcd 3.36)

The prepolymers were found to be storage-stable under $\mathrm{N}_{2}$ for periods up to even 5-6 months without any apparent change in the isocyanate content. As a model, the prepolymer from PTMG856 was end-capped with phenol (4 in Table II) in order to study its dissociation characteristics. In the chain-extention stage, the prepolymer was dissolved in diglyme under $\mathrm{N}_{2}$ followed by the addition of a diglyme solution of bisphenol-A (or the solution of phenol in case of end-capping). The contents were stirred for an additional two hours at $100^{\circ} \mathrm{C}$ and poured into methanol. The volume of diglyme, added during the chain-extension stage, was adjusted so as to give a polymer concentratiorr of about $5-10 \% \mathrm{w} / \mathrm{v}$ in diglyme. The products were repeatedly reprecipitated from diglyme solutions into methanol and dried under vacuum at $40-50^{\circ} \mathrm{C}$ for at least 24 hours.

\section{Dissociation Procedure}

The method used for the dissociation was essentially the same as that of Lateef et al., ${ }^{8}$ except that the glass tubes employed for the dissociation studies were filled with the urethane solution and sealed as well under $\mathrm{N}_{2}$. The concentration of model compounds used was $0.065 \mathrm{moll}^{-1}$, and for the polymers, it was either $14 \% \mathrm{w} / \mathrm{v}$ (for the polyurethane polymer from PTMG-2000) or $10 \% \mathrm{w} / \mathrm{v}$ (for the polyurethane polymer from PTMG-856) in diglyme. The equilibrium condition was assumed when the concentrations of liberated isocyanate and the undissociated urethane compound remained unchanged, or in the case of polymers, when the concentration of liberated isocyanate remained almost constant, during three measurements spread over a period of at least 30 minutes. For model compounds, the equilibrium constant, $K$, was calculated from

$$
K=\frac{[\mathrm{RNCO}]^{m} \cdot\left[\mathrm{R}^{\prime} \mathrm{OH}\right]^{n}}{[\text { Urethane }]}
$$

where $m=n=1$ for (1) $m=2, n=1$ for (2) and (4) and $m=1, n=2$ for (3). $\Delta H$ and $\Delta S$ were determined by plotting $\Delta G$ against $T . \Delta G$, in turn, was calculated from, $\log K=-(\Delta G / 2.303 R) \cdot(1 / T)$.

For polymers, the dissociation data are treated in terms of percent urethane bonds cut and average number of cuts per molecule. ${ }^{10}$

The number of urethane bonds, $N_{\mathrm{u}}$, was calculated according to

$$
N_{\mathrm{u}}=2\left[M_{n}-M_{\mathrm{ter}}\right] / M_{\text {rep }}
$$

where $M_{n}=$ mol wt of the parent polymer

$$
\begin{aligned}
M_{\mathrm{ter}}= & \text { mol wt of one terminal unit, e.g., in } \\
& \text { case of parent polymer, the terminal } \\
& \text { unit is a bisphenol moiety (228), and } \\
& \text { in case of dissociated polymer it is }
\end{aligned}
$$


an MDI unit (250),

$M_{\text {rep }}=$ mol wt of a repeating unit, and

$M_{n(t)}=\mathrm{mol} \mathrm{wt} \mathrm{at} \mathrm{time} t$.
The factor 2 in (1) appears because of two aromatic (dissociable) urethane bonds present per repeating unit and can be represented as,

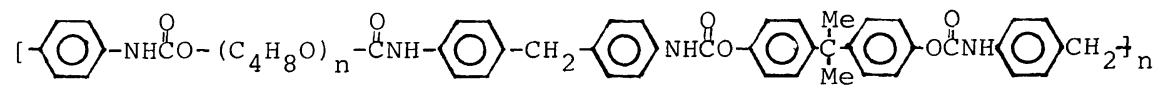

The average no. of links ruptured per chain, $S$, is given by,

$$
S+1=X_{0} / X_{t}
$$

where, $X_{0}$ and $X_{t}$ stand for degree of polymerization at time 0 and $t$.

\section{Procedure for Trapping of Isocyanates}

The urethane-diglyme solution, following dissociation, was poured into THF or dimethylformamide (DMF) containing the amine, and stirred at room temperature, and after confirming the complete absence of the isocyanate by IR, it was poured into a large volume of methanol or water, filtered and dried. In the process of finding suitable conditions for trapping, various amines were employed, such as butylamine, and dibutylamine, aniline, $o$-chloroaniline, and $p$-chloroaniline. Except $o$-chloroaniline, all other amines were found to affect the urethane linkage in model compounds even at room temperature (and even before dissociation). In case of $o$-chloroaniline, where such a phenomenon was not noticed, unidentified side products were found in small but detectable quantities in the course of trapping, as confirmed by thin-layer chromatography (TLC) (silica gel, benzene: $\mathrm{THF}=98: 2 \mathrm{v} / \mathrm{v}$ ). The side products, whose structures could not be established by the available data, were separated by preparative TLC, or column chromatography, and their characteristics are shown below.

From [1]: mp $60-70^{\circ} \mathrm{C}$; IR $3600(-\mathrm{OH}), 3280$ $(-\mathrm{NH}), 2920,1740$ (urethane $\mathrm{C}=\mathrm{O}$ ), 1640 (amide $\mathrm{C}=\mathrm{O}$ ), and $1530 \mathrm{~cm}^{-1}$.

From [2]: $\mathrm{mp} 230^{\circ} \mathrm{C}$; IR $3300,1700,1640$, and $1530 \mathrm{~cm}^{-1}$. Found: C, $73.00 \% ; \mathrm{H}, 6.22 \% ; \mathrm{N}$, $12.37 \%$.

\section{RESULTS AND DISCUSSION}

The thermal dissociation of aryl urethanes was found to occur in various solvents, as seen in Table I. It was thus clear that keto and aliphatic polyether
Table I. Dissociation of 1 in organic solvents ${ }^{\mathrm{a}}$

\begin{tabular}{lc}
\hline \multicolumn{1}{c}{ Solvent } & Inference \\
\hline Acetone & + \\
Methyl ethyl ketone & + \\
Methyl $i$-butyl ketone & + \\
Glyme $^{\mathrm{b}}$ & + \\
Diglyme & + \\
Triglyme & + \\
$N, N$-Dimethylacetamide & - \\
$o$-Dichlorobenzene & - \\
Ethyl benzoate & - \\
Tetrahydrofuran & - \\
\hline
\end{tabular}

a At $100^{\circ} \mathrm{C}$.

b From ref 8.

solvents seemed most suitable for the present dissociation study. Comparison of the extent of dissociation in these two types of solvents revealed that urethanes dissociate to a higher extent in aliphatic polyether solvents. Representative of these solvents, diglyme was chosen and all the dissociation studies reported in this article were performed in this solvent only.

The dissociation of an urethane linkage can be written as

\section{$\mathrm{RNHCOOR}^{\prime} \longrightarrow \mathrm{RNCO}+\mathrm{HOR}^{\prime}$}

The progress in the dissociation reaction can be studied by following the changes in the concentrations of the urethane and the isocyanate with time, and the IR technique proved to be very useful. We also found this type of dissociation reaction to be very rapid and reaching equilibrium, in case of model compounds, in a short period of time; e.g., for 2 , the equilibrium was reached in $20 \mathrm{~min}$ at $110^{\circ} \mathrm{C}$, in $15 \mathrm{~min}$ at $130^{\circ} \mathrm{C}$, and in $10 \mathrm{~min}$ at $150^{\circ} \mathrm{C}$. For polymers, the time for equilibrium varied from 30 to $70 \mathrm{~min}$, depending on the dissociation temperature.

Equilibrium constants and the thermodynamic 
Table II. Dissociation of model urethane compounds ${ }^{\mathrm{a}}$

\begin{tabular}{|c|c|c|c|c|c|c|c|c|}
\hline \multirow{2}{*}{ Compound } & \multicolumn{3}{|c|}{$\begin{array}{l}\text { Weight percent dissociation } \\
\text { of urethane at equilibrium }\end{array}$} & \multicolumn{3}{|c|}{$K \times 10^{-3 \mathrm{~b}}$} & \multirow{2}{*}{$\frac{\Delta H}{\mathrm{kcal} \mathrm{mol}^{-1}}$} & \multirow{2}{*}{$\frac{\Delta S}{\text { e.u. }}$} \\
\hline & $110^{\circ} \mathrm{C}$ & $130^{\circ} \mathrm{C}$ & $150^{\circ} \mathrm{C}$ & $110^{\circ} \mathrm{C}$ & $130^{\circ} \mathrm{C}$ & $150^{\circ} \mathrm{C}$ & & \\
\hline 1 & $\begin{array}{c}34.5 \\
{[19.2]^{\mathrm{c}}}\end{array}$ & $\begin{array}{c}45.4 \\
{[24.9]}\end{array}$ & $\begin{array}{c}66.6 \\
{[32.0]}\end{array}$ & $\begin{array}{l}11.6 \\
(15)^{\mathrm{d}}\end{array}$ & $\begin{array}{l}23.6 \\
(12)\end{array}$ & $\begin{array}{l}64 \\
(5)\end{array}$ & 13.1 & 25 \\
\hline 2 & $\begin{array}{l}31.4 \\
{[8.0]}\end{array}$ & $\begin{array}{c}49.3 \\
{[13.5]}\end{array}$ & $\begin{array}{c}66.5 \\
{[18.0]}\end{array}$ & $\begin{array}{c}0.0224 \\
(20)\end{array}$ & $\begin{array}{c}0.156 \\
(15)\end{array}$ & $\begin{array}{c}0.752 \\
(10)\end{array}$ & 25.9 & 42.8 \\
\hline 3 & $\begin{array}{c}20.0 \\
{[12.0]}\end{array}$ & $\begin{array}{c}37.5 \\
{[21.0]}\end{array}$ & $\begin{array}{c}54.3 \\
{[26.0]}\end{array}$ & $\begin{array}{c}0.0464 \\
(21)\end{array}$ & $\begin{array}{c}0.38 \\
(10)\end{array}$ & $\begin{array}{r}0.87 \\
(7)\end{array}$ & 23.9 & 42.7 \\
\hline 4 & $\begin{array}{r}8.7 \\
{[8.0]}\end{array}$ & $\begin{array}{c}20.5 \\
{[18.0]}\end{array}$ & $\begin{array}{c}24.5 \\
{[23.0]}\end{array}$ & $\begin{array}{c}2.3 \times 10^{-4} \\
(20)\end{array}$ & $\begin{array}{c}2.9 \times 10^{-3} \\
(20)\end{array}$ & $\begin{array}{l}5.8 \times 10^{-3} \\
(15)\end{array}$ & 26.2 & 40 \\
\hline
\end{tabular}

a Concentration, $0.065 \mathrm{moll}^{-1}$ in diglyme.

b $K$ in appropriate units.

c Figures in square brackets indicate isocyanate concentration $(\mathrm{wt} \%)$.

d Figures in parenthesis indicate time in minutes to reach equilibrium.

parameters for the thermal dissociation of model compounds are shown in Table II. The $\Delta H$ and $\Delta S$ values appear to be of the same order of magnitude reported for the thermal dissociation process. ${ }^{8}$ The $\Delta H$ and $\Delta S$ values of the compounds 2,3 , and 4 are two times to those of $\mathbf{1}$ indicating thus the dissociation of both the urethane linkages in all the bisurethane compounds, at equilibrium. [note: The term "urethane" linkage, frequently referred to in the case of these bisurethanes and the polyurethane polymers, corresponds to that urethane linkage only between aromatic counterparts]. The dissociation of the two urethane linkages in the case of model compounds 2, 3, and 4 at equilibrium was also confirmed by GPC measurements on the dissociated mass directly. The dissociation of $\mathbf{2}$ is shown in Figure 1. The back reactions, as observed within the IR cell at room temperature, were found to be quite slow for all aryl urethanes listed earlier in this article. Fortunately, these slow back reactions permitted an accurate determination of concentrations of the isocyanate and the urethane within the time required for the measurement. The addition of catalysts like pyridine, $\mathrm{Et}_{3} \mathrm{~N}$, or dibutyltin dilaurate to hasten up the back reaction was found to induce undesirable side reactions.

From a set of separate experiments employing model aliphatic urethanes such as EtOCONHPh, or

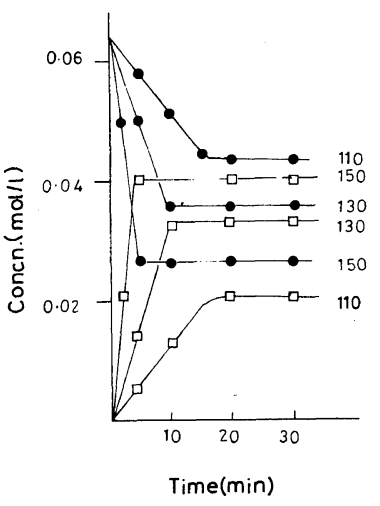

Figure 1. Dissociation of 2 at various temperatures: ○, 2; $\square, \mathrm{PhNCO}$.

$n$-BuOCONHPh, we found that under the conditions of dissociation used in this study, the aliphatic urethane bonds were not cleaved even to a detectable extent. These results conclusively showed that in the.dissociation of the polyurethane polymers synthesized in this study and which contain both aliphatic and aromatic urethane linkages, only the latter are cleaved.

The evaluation of the equilibrium constant and other thermodynamic parameters for polymer dissociation proved to be relatively difficult because of 
Thermal Dissociation of Urethanes

Table III. Dissociation of polyurethane polymer from PTMG- 856 at $140^{\circ} \mathrm{C}^{\mathrm{a}}$

\begin{tabular}{cccccc}
\hline Time & \multicolumn{2}{c}{ Concentration of $-\mathrm{NCO}$} & & & \\
\cline { 2 - 3 } $\min$ & $\mathrm{wt} \%$ & $M_{n}(t)$ & $\overline{D P}$ & $N_{\mathrm{u}}$ & $M_{n} / M_{n}(t)$ \\
\cline { 2 - 5 } 2 & 10.08 & 13412 & 8.47 & 16.62 & 1.032 \\
5 & 10.83 & 13291 & 8.39 & 16.47 & 1.041 \\
10 & 13.68 & 10662 & 6.73 & 13.15 & 1.298 \\
15 & 13.88 & 10457 & 6.60 & 12.89 & 1.323 \\
20 & $(13.10)$ & $(10772)$ & $(6.80)$ & $(13.29)$ & $(1.284)$ \\
30 & 14.11 & 10299 & 6.50 & 12.69 & 1.343 \\
40 & 14.70 & 10121 & 6.39 & 12.46 & 1.367 \\
50 & 16.97 & 9330 & 5.89 & 11.47 & 1.483 \\
70 & 16.87 & 9400 & 5.93 & 11.55 & 1.472 \\
90 & 16.96 & 9280 & 5.86 & 11.40 & 1.491 \\
\hline
\end{tabular}

a $M_{n}=13835$ : concentration, $10 \% \mathrm{w} / \mathrm{v}$ in diglyme.

Table IV. Dissociation of polyurethane polymer from PTMG-856 ${ }^{\mathrm{a}}$

\begin{tabular}{|c|c|c|c|c|c|c|c|c|c|c|c|c|}
\hline \multirow{3}{*}{$\frac{\text { Time }}{\min }$} & \multicolumn{4}{|c|}{ Concentration of $-\mathrm{NCO}$} & \multirow{2}{*}{\multicolumn{4}{|c|}{$\%$ Urethane bonds cut }} & \multirow{2}{*}{\multicolumn{4}{|c|}{ Average no. of cuts per chain }} \\
\hline & \multicolumn{4}{|c|}{$\mathrm{wt} \%$} & & & & & & & & \\
\hline & $110^{\circ} \mathrm{C}$ & $130^{\circ} \mathrm{C}$ & $140^{\circ} \mathrm{C}$ & $150^{\circ} \mathrm{C}$ & $110^{\circ} \mathrm{C}$ & $130^{\circ} \mathrm{C}$ & $140^{\circ} \mathrm{C}$ & $150^{\circ} \mathrm{C}$ & $110^{\circ} \mathrm{C}$ & $130^{\circ} \mathrm{C}$ & $140^{\circ} \mathrm{C}$ & $150^{\circ} \mathrm{C}$ \\
\hline 5 & $* \mathbf{b}$ & 10.82 & 10.83 & 11.33 & $*$ & 3.1 & 4.1 & 17.5 & $*$ & 0.029 & 0.041 & 0.205 \\
\hline 10 & $*$ & 11.18 & 13.68 & 13.52 & $*$ & 9.8 & 23.5 & 21.7 & $*$ & 0.105 & 0.298 & 0.269 \\
\hline 15 & $一^{c}$ & 11.74 & 13.88 & 15.99 & - & 19.0 & 25.0 & 32.1 & - & 0.228 & 0.323 & 0.458 \\
\hline 20 & 10.2 & 12.18 & $(13.10)$ & $(15.30)$ & 10.9 & 19.5 & $(22.6)$ & $(29.2)$ & 0.119 & 0.235 & $(0.284)$ & $(0.399)$ \\
\hline 30 & 10.33 & 12.56 & 14.11 & 17.05 & 12.1 & 21.0 & 26.1 & 35.0 & 0.132 & 0.258 & 0.343 & 0.520 \\
\hline 40 & 11.00 & 13.53 & 14.70 & 17.11 & 12.7 & 22.9 & 27.5 & 35.4 & 0.141 & 0.288 & 0.367 & 0.530 \\
\hline 50 & - & - & 16.97 & 17.88 & - & - & 33.2 & 36.8 & - & - & 0.483 & 0.563 \\
\hline 60 & 11.29 & 14.07 & - & 17.88 & 14.1 & 25.8 & - & 37.1 & 0.160 & 0.337 & - & 0.572 \\
\hline 70 & 11.42 & 14.09 & 16.87 & 17.87 & 17.1 & 26.1 & 32.8 & 37.2 & 0.200 & 0.342 & 0.472 & 0.573 \\
\hline \multicolumn{5}{|c|}{ (at $\left.80^{\prime}\right)$} & \multicolumn{2}{|c|}{ (at $\left.80^{\prime}\right)$} & & & \multicolumn{2}{|c|}{ (at $\left.80^{\prime}\right)$} & & \\
\hline 90 & \multicolumn{2}{|c|}{$\left(\right.$ at $\left.100^{\prime}\right)$} & 16.96 & 17.87 & \multicolumn{2}{|c|}{ (at $\left.100^{\prime}\right)$} & 33.6 & 36.7 & $\begin{array}{r}0.194 \\
\text { (at }\end{array}$ & $\begin{array}{c}0.345 \\
\left.100^{\prime}\right)\end{array}$ & 0.491 & 0.562 \\
\hline 120 & 11.38 & - & - & - & 17.4 & - & - & - & 0.196 & - & - & - \\
\hline
\end{tabular}

a $M_{n}=13835$; concentration, $10 \% \mathrm{w} / \mathrm{v}$ in diglyme.

b No detectable dissociation.

c Not determined.

the difficulty in determining the concentrations of dissociated and undissociated polymers, necessary for calculating $K$ by following generally the changes in urethane $\mathrm{C}=\mathrm{O}$ intensity in the IR. Consequently only the change in the isocyanate concentration was followed (to correlate with the change in the molecular weight). Thus the polymer dissociation data are reported in this study in terms of the percent urethane bonds (see the note above) cut, and average number of cuts per chain..$^{10}$ These data are presented in Tables IV, V, and Figures 2 and 3. In Table III are recorded, as a typical example, the detailed dissociation data at $140^{\circ} \mathrm{C}$ for polyurethane polymer from PTMG-856.

In order to qualitatively correlate the dissociation characteristics of the model compounds with the polyurethane polymers, let us consider the respective data of dissociation at $150^{\circ} \mathrm{C}$. For example, 
Table V. Dissociation of polyurethane polymer from PTMG-2000

\begin{tabular}{|c|c|c|c|c|c|c|c|c|c|}
\hline \multirow{3}{*}{$\frac{\text { Time }}{\min }$} & \multicolumn{3}{|c|}{ Concentration of $-\mathrm{NCO}$} & \multirow{2}{*}{\multicolumn{3}{|c|}{$\%$ Urethane bonds cut }} & \multirow{2}{*}{\multicolumn{3}{|c|}{ Average no. of cuts per chain }} \\
\hline & \multicolumn{3}{|c|}{$w t \%$} & & & & & & \\
\hline & $110^{\circ} \mathrm{C}$ & $130^{\circ} \mathrm{C}$ & $150^{\circ} \mathrm{C}$ & $110^{\circ} \mathrm{C}$ & $130^{\circ} \mathrm{C}$ & $150^{\circ} \mathrm{C}$ & $110^{\circ} \mathrm{C}$ & $130^{\circ} \mathrm{C}$ & $150^{\circ} \mathrm{C}$ \\
\hline 5 & $* \mathrm{~b}$ & 7.43 & 11.5 & $*$ & 16.8 & 44.7 & $*$ & 0.196 & 0.792 \\
\hline 10 & 7.2 & 7.54 & 11.55 & 13.6 & 17.7 & 47.7 & 0.155 & 0.212 & 0.893 \\
\hline 15 & $-^{c}$ & 7.84 & 12.2 & - & 20.6 & 50.6 & - & 0.256 & 1.000 \\
\hline 20 & 7.46 & $\begin{array}{c}8.91 \\
\text { (at } 25^{\prime} \text { ) }\end{array}$ & 12.36 & 15.8 & $\begin{array}{c}30.5 \\
\text { (at } 25^{\prime} \text { ) }\end{array}$ & 51.1 & 0.184 & $\begin{array}{c}0.433 \\
\left.\text { (at } 25^{\prime}\right)\end{array}$ & 1.025 \\
\hline 30 & 7.73 & $\begin{array}{c}7.97 \\
\text { (at } 35^{\prime} \text { ) }\end{array}$ & - & 19.6 & $\begin{array}{c}26.2 \\
\text { (at } 35^{\prime} \text { ) }\end{array}$ & - & 0.242 & $\begin{array}{c}0.349 \\
\text { (at } 35^{\prime} \text { ) }\end{array}$ & - \\
\hline 40 & 7.93 & - & 12.3 & 23.84 & - & 50.9 & 0.308 & - & 1.016 \\
\hline 50 & 8.16 & 9.53 & - & 23.7 & 35.0 & - & 0.307 & 0.528 & - \\
\hline 60 & 8.24 & 9.61 & 12.2 & 24.7 & 35.3 & 50.5 & 0.322 & 0.538 & 0.999 \\
\hline 80 & 8.46 & $\begin{array}{c}9.44 \\
\text { (at } 85^{\prime} \text { ) }\end{array}$ & - & 26.4 & $\begin{array}{c}35.7 \\
\text { (at } 85^{\prime} \text { ) }\end{array}$ & - & 0.354 & $\begin{array}{c}0.544 \\
\text { (at } 85^{\prime} \text { ) }\end{array}$ & - \\
\hline 100 & 8.38 & - & - & 25.7 & - & - & 0.341 & - & - \\
\hline 120 & 8.44 & - & - & 26.2 & - & - & 0.349 & - & - \\
\hline
\end{tabular}

a $M_{n}=25987$; concentration, $14 \% \mathrm{w} / \mathrm{v}$ in diglyme.

b No detectable dissociation.

c Not determined.

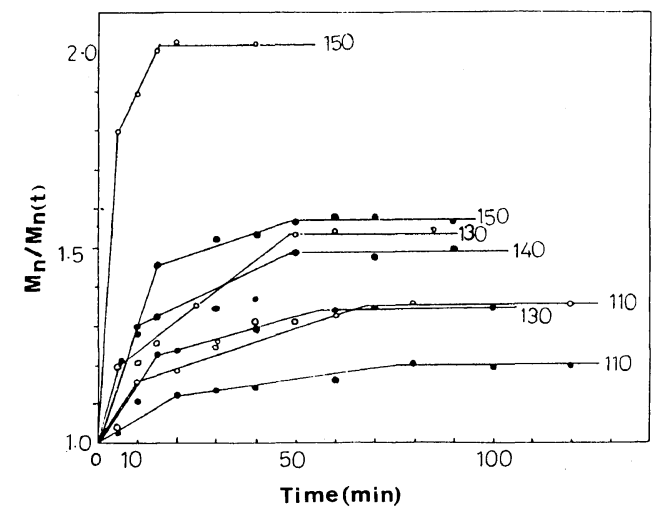

Figure 2. Thermal dissociation of polyurethane polymers at different temperatures: polymer from PTMG-856; O, polymer from PTMG-2000.

from Figure 1, the extent of dissociation of $\mathbf{1}$ is 67 $\mathrm{mol} \%$. Similarly, for $\mathbf{2}$, and 3 , the values are $\sim 66-7$ $\mathrm{mol} \%$, thus showing that the aromatic urethane bonds in these model compounds behave in a similar manner. When the aromatic urethane bonds in the molecule are intercepted by long, nonaromatic portions, as in $\mathbf{4}$, the dissociation drops to $50 \mathrm{~mol} \%$ (note: In $\mathbf{4}$, there are present two aromatic

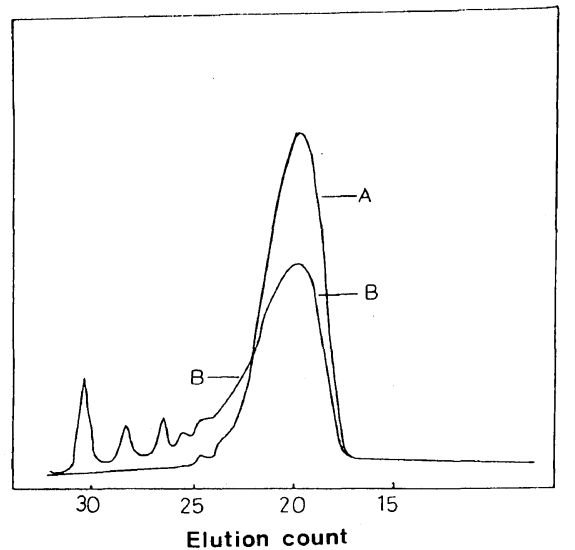

Figure 3. GPC traces of polyurethane polymer: A, polyurethane polymer from PTMG-856; B, the same polymer after dissociation at $150^{\circ} \mathrm{C}$ for 90 minutes.

urethane and two non-aromatic urethane bonds), under identical conditions of dissociation. In $\mathbf{4}$, the long, non-aromatic portion is the poly(oxytetramethylene) chain, and the influence of this part of the molecule on the dissociation characteristics, although still unclear cannot be ruled out. The dissociation of polyurethane polymer- 2000 
tallies well with this value $(51 \%)$ while the slightly low value of $37 \%$ for polyurethane polymer- 856 may be attributed to the higher concentration of urethane bonds in the latter.

Next, we should like to make some comments on the trapping experiments in which we attempted to trap by amines the $-\mathrm{NCO}$ terminated fragments produced in the dissociation of polyurethane polymers. Initial experiments employing $o$ chloroaniline in THF (or DMF or dimethylacetamide (DMA)) followed by reprecipitation in methanol revealed that in some cases, there was almost no change in the molecular weight of the parent polymer, whereas the IR indicated an appreciable degree of dissociation in the parent polymer. Similar results were observed with other amines, such as butylamine, dibutylamine, $p$ chloroaniline, and aniline. The reasons for this remain unclear but might be some unknown reaction between the formed $-\mathrm{NCO}$ terminated polymer fragment and the parent polymer (see, for example, EXPERIMENTAL section). Accordingly, we thought of using the dissociated polymer samples, after suitable dilution with THF, directly for GPC measurements and found it to be effective.

It is of interest to note, though, that Hegarty and Frost $\mathrm{t}^{11}$ have not reported the formation of any side product in the process of trapping of liberated free isocyanate by $o$-chloroaniline in their investigation on the hydrolytic studies of the model monoaryl urethanes in aqueous medium. We strongly believe that the conditions of trapping may play an important role because our trapping was performed in organic solvents under the conditions of complete homogeneity and in the absence of water.

Acknowledgement. One of the authors (R.A.N.M.) is grateful to the Ministry of Education, Science, and Culture, Japan, for the award of a scholarship.

\section{REFERENCES}

1. N. G. Gaylord and C. E. Sroog, J. Org, Chem., 25, 1874 (1960).

2. T. Mukaiyama and T. Akiba, Bull. Chem. Soc. Jpn., 33, 1707 (1960).

3. M. S. Fedoseev, G. N. Marchenko, and N. G. Rogov, Sin Fiz.-Khim. Polim., 158 (1970); Chem. Abstr., 75, 48233d (1971).

4. T. Furuya, S. Goto, K. Itoh, I. Urasaki, and A. Morita, Tetrahdedron, 24, 2367 (1968).

5. T. Hoshino, T. Mukaiyama, and H. Hoshino, Bull. Chem. Soc. Jpn., 25, 396 (1952).

6. A. M. Tartakovskaya, A. A. Blagonravova, and Yu. A. Strepikheev, i) Lakokrasoch. Mater, Ikh. Primen., 1 (1967); Chem. Abstr., 68, 59196a (1968); ii) Vysokomol. Soedin., Ser. B, 12, 84 (1970); Chem. Abstr., 73, 110606 (1970).

7. M. S. Fedoseev, G. N. Marchenko, and L. K. Kiryanova, Sin. Fiz-Khim. Polim., 163 (1970); Chem. Abstr., 75, 48232c (1971).

8. A. B. Lateef, J. A. Reeder, and L. Rand, J. Org. Chem., 36, 2295 (1971).

9. R. Rosenthal and J. G. Zajacek, (Atlantic Richfield Co.), U. S. Patent 3,962,302 (1976); Chem. Abstr., 85, 177053a (1976).

10. R. Simha, J. D. Ingham, N. S. Rapp, and J. Hardy, J. Polym. Sci., B, 2, 675 (1964).

11. A. F. Hegarty and L. N. Frost, J. Chem. Soc., Perkin Trans., 2, 1719 (1973). 